\title{
IDENTIFIKASI JAMUR PADA LALAT DI YAYASAN TUNAS MULIA BANTAR GEBANG
}

\author{
Ika Nurfitrianti ${ }^{1}$, Maulin Inggraini ${ }^{2}$, Noor Andryan Ilsan ${ }^{3 *}$ \\ 1. Program Studi DIII Analis Kesehatan, STIKes Mitra Keluarga, Bekasi-Indonesia \\ 2. Program Studi DIII Analis Kesehatan, STIKes Mitra Keluarga, Bekasi-Indonesia \\ 3. Program Studi DIII Analis Kesehatan, STIKes Mitra Keluarga, Bekasi-Indonesia \\ *Korespondensi: Noor Andryan Ilsan | STIKes Mitra Keluarga |noorandryanilsan@ gmail.com
}

\begin{abstract}
Abstrak
Pendahuluan: Yayasan Tunas Mulia, Bantar Gerbang merupakan sekolah alam yang terdapat di daerah Bantar Gebang. Siswa Yayasan Tunas Mulia tinggal didaerah TPST Bantar Gebang sehingga banyak ditemukan lalat di sekitar tempat tinggal mereka. Kelompok lalat yang sering kita temui di lingkungan yaitu lalat rumah, lalat hijau dan lalat daging. Lalat dapat menularkan berbagai macam penyakit terutama penyakit yang disebabkan oleh jamur. Tujuan penelitan ini adalah untuk mengidentifikasi jamur pada lalat di Yayasan Tunas Mulia Bantar Gebang.

Metode: Metode penelitian ini secara Cross Sectional yaitu mencuplikan seekor sampel lalat dalam satu waktu. Objek penelitian adalah Lalat yang ditangkap di Yayasan Tunas Mulia Bantar Gebang.

Hasil: Hasil yang diperoleh dari penelitian ini adalah didapatkan dua jenis spesies lalat yaitu Musca domestica dan Chrysomya megachepala. Jamur yang di dapatkan pada permukaan tubuh lalat Musca domestica yaitu Aspergillus niger, Aspergillus flavus, Fusarium oxysporum, dan pada permukaan tubuh lalat Chrysomya megachepala yaitu Aspergillus fumigatus dan Aspergillus flavus

Kesimpulan: Perlu dilakukan penelitian lanjutan untuk mengetahui penyakit yang disebabkan oleh jamur dari penyebaran lalat dilingkungan masyarakat.
\end{abstract}

Kata Kunci: Lalat, Vektor, Jamur.

Diterima 23 Juli 2019; Accepted 30 Desember 2019

\section{PENDAHULUAN}

Lalat merupakan jenis seranggga yang termasuk ordo Diptera dan hidupnya dekat dengan lingkungan manusia. Kelompok lalat yang berdekatan dengan manusia adalah lalat rumah, lalat hijau, dan lalat daging. Menurut Hastutie \& Fitri (2007) dalam bidang kesehatan lalat dianggap sebagai serangga pengganggu karena merupakan vektor mekanis. Vektor mekanis merupakan vektor yang membawa agen penyakit dan menularkannya kepada inang melalui kaki-kakinya ataupun seluruh bagian luar tubuhnya dimana agent penyakitnya tidak mengalami perubahan bentuk maupun jumlah dalam tubuh vektor. Serangga yang termasuk ke dalam vektor mekanik antara lain kecoa dan lalat. Lalat juga dapat mengganggu dari segi kebersihan dan ketenangan.

Menurut Arroyo HS (1998) seekor lalat dapat membawa sekitar lebih dari 100 macam organisme patogen yang dapat menyebabkan penyakit pada manusia dan hewan. Selama ini lalat dikenal hanya dapat menyebabkan penyakit secara tidak langsung karena perannya sebagai perantara berbagai penyakit. Menurut Sembel (2009) mikroorganisme patogen yang terbawa oleh lalat dapat mengakibatkan penyakit pada manusia di antaranya adalah tipoid, paratipoid, kolera, disentri, tuberkulosis, dan kecacingan. Menurut penelitian yang telah dilakukan Aminah, dkk (2005) menyatakan bahwa didaerah DKI Jakarta di dapatkan beberapa jenis jamur dari kaki lalat yaitu Penicillin, Aspergillus niger, Aspergillus flavus, Aspergillus fumigatus, Mucor.sp, Rhizopus sp Menurut Prasetyaningsih, dkk (2015) toksin yang dihasilkan oleh Aspergillus flavus dapat menyerang sistem saraf pusat, beberapa diantaranya bersifat karsinogenik menyebabkan kanker pada hati, ginjal, dan perut. Menurut Shahid et.al (2001) jamur Aspergilus fumigatus merupakan penyebab $90 \%$ infeksi pada paru-paru.

Tempat Pembuangan Sampah Terpadu (TPST) Bantar Gebang secara administratif berada di Kota Bekasi. Secara fungsional TPST Bantar Gebang merupakan tempat pembuangan sampah yang berasal dari Provinsi DKI Jakarta dan Kota Bekasi. TPST Bantar Gebang memiliki luas total daerah 110,3 Ha. Terletak di Kota Bekasi. Posisi TPST dikelilingi oleh 4 kelurahan, yaitu Kelurahan Cikiwul, Kelurahan Sumur Batu, dan Kelurahan Ciketing Udik. TPST Bantar Gebang menampung sampah yang berasal dari DKI seluas 85 Ha, dan sampah yang berasal dari Kota Bekasi seluas 27 Ha. Zona pembuangan DKI Jakarta setiap hari 
menampung kurang lebih 5.000 ton, dan sampah dari kota Bekasi kurang lebih 1.000 ton perhari. Mayoritas masyarakat Bantar Gebang berprofesi sebagai buruh (Maulana, dkk, 2014).

Yayasan Tunas Mulia, Bantar Gerbang merupakan sekolah alam yang terdapat di daerah Bantar Gebang. Siswa yang belajar di Yayasan Tunas Mulia tinggal didaerah TPST Bantar Gebang yang dilingkungan sekitarnya banyak sekali ditemukan sampah. Sehingga banyak ditemukan lalat disekitar tempat tinggal mereka dan tempat belajar mereka.

\section{METODE}

Jenis penelitian yang dilakukan adalah Deskriptif dengan pengambilan sampel secara Cross Sectional dari semua jenis lalat yang terdapat di Yayasan Tunas Mulia Bantar Gebang dan pemeriksaan sampel lalat di lakukan dilaboratorium Bakteriologi Program Studi DIII Teknologi Laboratorium Medik STIKes Mitra Keluarga pada bulan September - Oktober 2017. Dengan menentukan 7 titik tempat di Yayasan Tunas Mulia Bantar Gebang Populasi sampel yaitu seluruh jenis lalat yang berhasil ditangkap menggunakan sweep net di Yayasan Tunas Mulia Bantar Gebang pada hari Jumat tanggal 29 September 2017 pada pukul 09:00 - 11:00.

Lalat yang telah dikumpulkan lalu di identifikasi jenisnya menggunakan buku acuan identifikasi lalat yang dipakai yaitu "Key to the adults of the most common forensic species of Diptera in South America". Lalat yang sudah diketahui jenisnya dikelompokkan berdasarkan jenisnya dan ditimbang. 1 gram jenis lalat dimasukan kedalam $9 \mathrm{ml}$ Nacl 0,9\%. Sampel dilakukan pengenceran bertingkat dimasukan kedalam pengenceran $10^{-1}$ sampai $10^{-6}$ dengan pengenceran Nacl $0,9 \%$. Sampel pada 3 pengenceran terakhir masingmasing diambil $100 \mu$ untuk ditanam pada media Saboruraud Dextrose Agar (SDA). Media SDA diinkubasi selama 5 hari pada suhu $37^{\circ} \mathrm{C}$. Pengamatan dilakukan pada hari ke 5 secara makroskopis dengan menggunakan larutan Lactophenol Cotton Blue (LPCB) pada perbesaran 40x. jamur diidentifikasi menggunakan acuan buku yang berjudul "Description Medical Fungi Edisi ke 2".

\section{HASIL}

Penelitian dilakukan dengan menggunakan sampel lalat yang diambil di Yayasan Tunas Mulia Bantar Gebang mulai dari bulan September hingga Oktober 2017. Didapatkan 2 jenis spesies lalat yaitu Musca domestica dan Chrysomya megacepala. Jumlah lalat yang berhasil ditangkap disajikan dalam tabel 1 .

Tabel 1. Jumlah lalat yang berhasil ditangkap:

\begin{tabular}{cc}
\hline Jenis lalat & Jumlah \\
\hline Musca domestica & 8 \\
Chrysomya megacepala & 15 \\
\hline Total & 23 \\
\hline
\end{tabular}

Tabel 1. menyatakan bahwa total jumlah lalat yang berhasil ditangkap yaitu 23 lalat. Lalat jenis Musca domestica yaitu sebanyak 8 buah, dan lalat jenis Chrysomya megacepala sebanyak 15 buah. Lalat dapat menyebabkan berbagai macam penyakit karena di tubuhnya dapat membawa berbagai macam mikroorganisme. Menurut Kusoputranto (2002) Lalat juga sebagai vector penularan penyakit artinya lalat ini bersifat pembawa atau memindahkan penyakit dari satu tempat ke tempat lain. Setiap jenis lalat membawa jenis jamur yang berbeda, ada pula jamur yang sama. Hasil identifikasi jamur pada lalat dapat dilihat pada tabel 2 .

Tabel 2. Hasil identifikasi jamur pada lalat

\begin{tabular}{cc}
\hline Jenis lalat & Jenis jamur \\
\hline Musca domestica & Aspergillus niger \\
& Aspergillus flavus \\
& Fusarium oxysporum \\
\hline Chrysomya & Aspergillus fumigatus \\
megacepala & Aspergillus flavus \\
\hline
\end{tabular}


Tabel 2 Hasil identifikasi jamur pada lalat terlihat bahwa lalat dengan jenis spesies Musca domestica membawa 3 jenis jamur yaitu Aspergillus flavus, Aspergillus niger, dan Penicillium. Menurut Jawetz, dkk (1996) Aspergillus $s p$ terdapat di alam sebagai saprofit, tumbuh di daerah tropik dengan kelembaban yang tinggi.

\section{PEMBAHASAN}

Permukaan tubuh luar merupakan organ yang kontak secara langsung dengan habitat tempat hidupnya. Hal ini memungkinkan banyaknya jenis jamur yang dapat terbawa oleh tubuh Musca domestica karena tubuhnya memiliki banyak bulu dan terdapat cairan perekat pada kakinya. Jenis jamur yang dapat menimbulkan penyakit pada manusia adalah Aspergillus flavus dan Aspergillus niger, semuanya menular melalui transmisi inhalasi. Menurut Hasanah (2017) Aspergillus flavus adalah penyebab paling umum dari aspergilosis pada manusia. Aspergilosis adalah penyakit yang disebabkan oleh jamur Aspergillus. Sedangkan Aspergillus niger merupakan penyebab umum otomikosis. Menurut Imamto (2015) Otomikosis yaitu infeksi akut yang menyerang telinga bagian tengah yang di sebabkan oleh jamur. Menurut Dwiyana putri \& dkk (2014) Jamur Fusarium oxysporum merupakan patogen penyebab penyakit layu pada tanaman.

Aspergillus niger secara makroskopis memiliki ciri yaitu koloni berwarna coklat kehitaman dan dibagian pinggir berwarna putih (Ellis, Davis, dkk, 2007). secara mikroskopis Aspergillus niger memiliki ciri memiliki konidiofor yang transparan serta konidia yang berwarna hitam kecoklatan serta sporangium yang berbentuk bulat. Menurut Samson dkk (2000) klasifikasi Aspergillus niger yaitu:

$\begin{array}{ll}\text { Phylum } & \text { : Ascomycota } \\ \text { Class } & \text { : Eurotiomycetes } \\ \text { Ordo } & \text { : Eurotiales } \\ \text { Family } & : \text { Trichocomaceae } \\ \text { Genus } & \text { : Aspergillus } \\ \text { Spesies } & \text { : Aspergillus niger }\end{array}$

Aspergillus flavus memiliki ciri makroskopis yaitu koloni berwarna hijau kekuningan dibagian tengah dan berwarna putih dibagian pinggir koloni (Melsilawati \& Khotimah, 2012). Secara mikroskopis Aspergillus flavus memiliki ciri-ciri yaitu, memiliki konidiofor yang panjang, vesikel dan konidia yang berbentuk bulat. Hal ini sesuai dengan Koneman et al (1992) menyatakan bahwa Aspergillus flavus memiliki konidiofor yang panjang 400-800 $\mu \mathrm{m}$, dan memiliki konidia yang bulat, halus dan kasar. Menurut Samson dkk (2000) klasifikasi Aspergillus flavus:

$\begin{array}{ll}\text { Phylum } & \text { : Ascomycota } \\ \text { Class } & \text { : Eurotiomycetes } \\ \text { Ordo } & \text { : Eurotiales } \\ \text { Family } & \text { : Trichocomaceae } \\ \text { Genus } & \text { : Aspergillus } \\ \text { Spesies } & \text { : Aspergillus flavus }\end{array}$

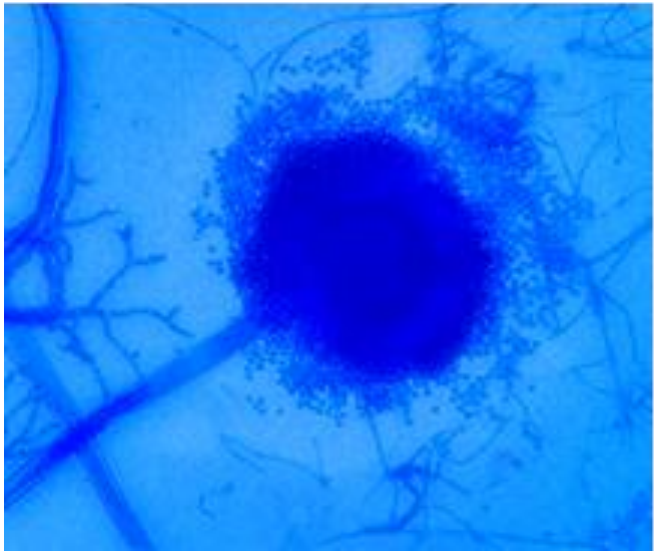

Gambar 4.1 Aspergillus niger secara mikroskopik 


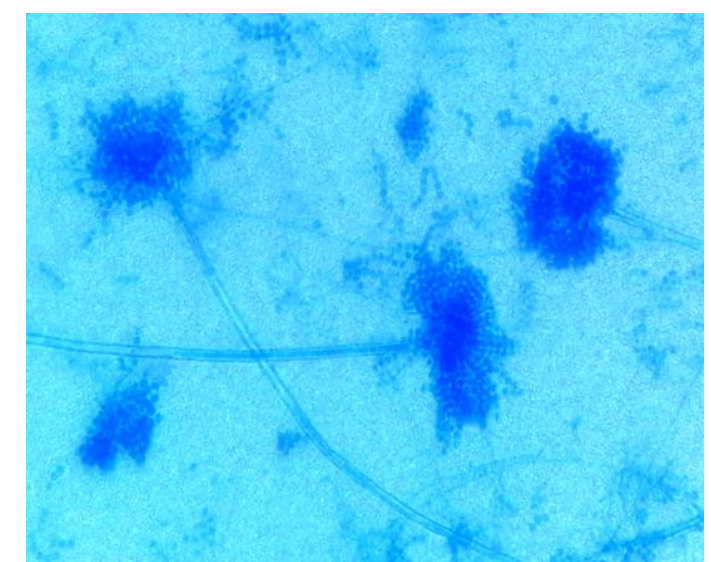

Gambar 4.2 Aspergillus flavus secara mikroskopik

Aspergillus fumigatus secara makoskopis memiliki ciri yaitu koloni berwarna hijau tua dan bertekstur kasar (Ellis, Davis, \& dkk, 2007). Secara mikroskopis memiliki ciri yaitu memiliki konidiofor , konidifora berseptat atau nonseptat. Pada strigma muncul konidium-konidium yang tersusun berurutan yang mendukung kepalanya yang besar (vesikel) dan dibagian kepalanya terdapat spora. Spesies Aspergillus sp secara alamiah terdapat dilingkungan yang kotor terutama pada sayuran basi, sampah daun dan kompos. Jamur yang ditemukan sesuai dengan lingkungan yang terdapat di Yayasan Tunas Mulia karena sangat berdekatan dengan tumpukan sampah. Suhu optimum pertumbuhan jamur Aspergillus fumigatus yaitu $37^{\circ} \mathrm{C}$. Menurut Samson dkk (2000) klasifikasi Aspergillus fumigatus :
Phylum : Ascomycota
Class : Eurotiomycetes
Ordo : : Eurotiales
Family : Trichocomaceae
Genus : Aspergillus
Spesies : : Aspergillus fumigatus

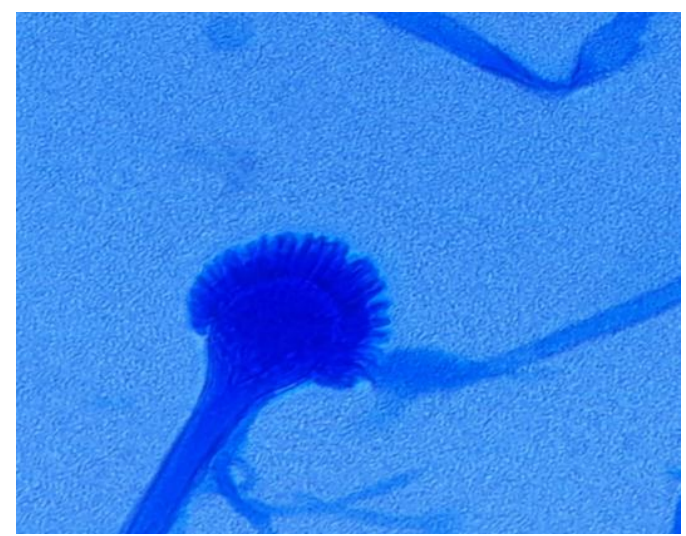

Gambar 4.3 Aspergillus fumigatus secara mikroskopik.

Fusarium oxysporum secara makroskopis memiliki ciri yaitu tekstur permukaan koloni seperti kapas halus berwarna putih hingga cream (Ellis, Davis, \& dkk, 2007). Menurut Samson dkk (1995) Fusarium secara mikroskopik memiliki tipe konidia berupa makrokonidia dan mikrokonidia, dan terdapat fialid. Menurut Semangun (1971) jamur Fusarium bersifat soil inhabitant sehingga dapat bertahan sangat lama sampai beberapa tahun didalam tanah tanpa adanya inang. Semangun (1996) klasifikasi Fusarium oxysporum:

Phylum : Ascomycota

Class : : Sordariomycetes

Ordo : Hypocreales 
$\begin{array}{ll}\text { Family } & \text { : Nectriaceae } \\ \text { Genus } & \text { : Fusarium } \\ \text { Spesies } & \text { : Fusarium oxysporum }\end{array}$

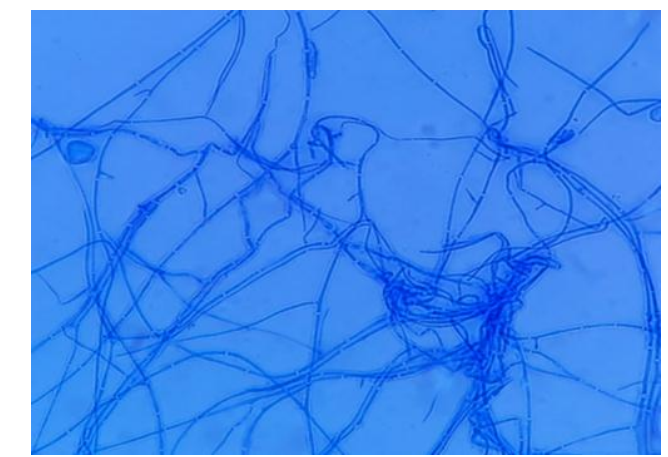

Gambar 4.4 Fusarium oxysporum secara mikroskopik

\section{KESIMPULAN}

Penelitian yang telah dilakukan di Yayasan Tunas Mulia Bantar Gebang, didapatkan dua jenis spesies lalat yaitu lalat Musca domestica dipermukaan tubuhnya terdapat jamur Aspergillus niger, Aspergillus flavus, dan Fusarium Oxysporum, dan lalat Chrysomya megachepala dipermukaan tubuhnya terdapat jamur Aspergillus fumigatus dan Aspergillus flavus.

Perlu dilakukan penelitian lanjutan untuk mengetahui penyakit yang disebabkan oleh jamur dari penyebaran lalat dilingkungan masyarakat.

\section{UCAPAN TERIMA KASIH}

Pada kesempatan ini penulis menyampaikan ucapan terima kasih kepada :

1. Ibu Susi Hartati, Skp., M.Kep., Sp.Kep.An Ketua STIKes Mitra Keluarga

2. Ibu Maulin Inggraini, M.Si, selaku pembimbing karya tulis yang telah meluangkan waktu dan memberikan saran dalam penyelesaian jurnal ini.

3. Ibu Siti Nurfajriah, S.Pd., M.Si, selaku Kepala Prodi DIII Teknologi Laboratorium Medik.

4. Bapak Noor Andryan Ilsan, M.Si, selaku pembimbing akademik

5. Keluarga tercinta yang telah memberikan semangat dan dorongan serta dukungan moril maupun materil

6. Tim PKM, yang telah membantu penulis dalam menyelesaikan penelitian ini.

7. Teman - teman seperjuangan jurusan Teknologi Laboratorium Medik angkatan 2 yang banyak memberikan dukungan dalam pembuatan penelitian ini.

\section{REFERENSI}

Aminah, N., Mardiana, \& Supraptini. 2005. Jenis Jamur dan Lalat yang ditemukan pada makanan jajanan dari pasar dan warung di Jakarta. Media Litbang Kesehatan, Vol.17 No.1.

Arroyo, H.S. 1998. Distribution and importance. Life Cycle and description Damage Economic Injury Level Management, Depart of Entomology Nematology.

Dwiyana putri, O,. Sastrahidayat, Ika Rochdjatun,.Djauhari, Syamsuddin. 2014. Pengaruh metode inokulasi jamur Fusarium oxysporum f.sp. terhadap kejadian penyakit layu fusarium pada tanaman tomat. Jurnal HPT.

Ellis, D., Davis, S.,Alexiou, H.,Handke, R., Bartley, R.. 2007. Description of medical fungi. Australia: Adeliade.

Hasanah, U. 2017. Mengenal Aspergilosis, infeksi jamur Genus Aspergillus. Jurnal keluarga sehat sejahtera.

Hastutie, P., \& Fitri, L. E. 2007. Potensi (Musca domestica) Linn. Sebagai Vektor Beberapa Penyakit. Jurnal kedokteran Brawijaya, 23(3):125-136.

Imamto, M. 2015. Radang telinga luar. jurnal kesehatan, 6(2):201-210 
Jawetz . 1996. Mikrobiologi kedokteran edisi ke 20. Jakarta: Penerbit Buku Kedokteran Jakarta.

Konaman, E. 1992. Color atlas and text of diagnostic mikrobiology. United states of america: J.B Lippincott Company.

Kusoputranto. 2002. kesehatan lingkungan pemukiman dan perkotaan. FKM UI.

Maulana, Y. C., Rohmat, D., \& Ruhimat, M. 2014. Zonasi Tempat Pembuangan Sampah Terpadu (TPST) BantarGebang. Jurnal Gea.

Melsilawati, W., \& Khotimah, S. 2012. Jamur yang terdapat pada tubuh lalat rumah. Protobiont.

Prasetyaningsih, Y., Nadifah, F., \& Susilowati, I. 2015. Distribusi Jamur Aspergillus Flavus pada Petis Udang Yogyakarta. University Research Coloquium.

Samson, Robert., \& Pitt. J.I. 2000. Intergration of modern taxonomic methods for Penicillium and Aspergillus Classifaction. Harwood Scientific Publisher Amsterdam.

Sembel, D. 2009. Entomologi Kedokteran. Yogyakarta: Penerbit ANDI.

Semangun, H. 1996. Pengantar ilmu penyakit tumbuhan. Yogyakarta: Gajah Mada Press.

Shahid, M., Malik, A., \& Bhargava R. 2001. Prevalence of aspergilosis in chronic lung diseases,Indian. $J$ Med Microbiol, 19(2):201-205

Tumrasvin, W., \& Satoshi, S. 1978. Studies on medially important flies in thailand V. on 32 species belonging to the subfamilies muscinae and stomoxyinae including the taxonomic keys (Diptera: Muscide). Bull tokyo med Dent Univ, 25(4):201-207 